Marquette University

e-Publications@Marquette

$11-2005$

\title{
Spectroscopic and Thermodynamic Characterization of the E151D and E151A Altered Leucine Aminopeptidases from Aeromonas proteolytica
}

Krzysztof P. Bzymek

Utah State University

Sabina I. Swierczek

Utah State University

Brian Bennett

Marquette University, brian.bennett@marquette.edu

Richard C. Holz

Marquette University, richard.holz@marquette.edu

Follow this and additional works at: https://epublications.marquette.edu/physics_fac

Part of the Physics Commons

\section{Recommended Citation}

Bzymek, Krzysztof P.; Swierczek, Sabina I.; Bennett, Brian; and Holz, Richard C., "Spectroscopic and Thermodynamic Characterization of the E151D and E151A Altered Leucine Aminopeptidases from Aeromonas proteolytica" (2005). Physics Faculty Research and Publications. 26.

https://epublications.marquette.edu/physics_fac/26 
Marquette University

e-Publications@Marquette

\section{Physics Faculty Research and Publications/College of Arts and Sciences}

This paper is NOT THE PUBLISHED VERSION; but the author's final, peer-reviewed manuscript. The published version may be accessed by following the link in the citation below.

Inorganic Chemistry, Vol. 44, No. 23 (1 November 2005): 8574-8580. DOI. This article is (C) American Chemical Society Publications and permission has been granted for this version to appear in $\underline{\mathrm{e}}-$ Publications@Marquette. American Chemical Society Publications does not grant permission for this article to be further copied/distributed or hosted elsewhere without the express permission from American Chemical Society Publications.

\section{Spectroscopic and Thermodynamic Characterization of the E151D and E151A Altered Leucine Aminopeptidases from Aeromonas proteolytica}

Krzysztof P. Bzymek

Department of Chemistry and Biochemistry, Utah State University, Logan, Utah Sabina I. Swierczek

Department of Chemistry and Biochemistry, Utah State University, Logan, Utah Brian Bennett

University of Wisconsin, Milwaukee

Richard C. Holz

Department of Chemistry and Biochemistry, Utah State University, Logan, Utah

\section{SUBJECTS:}

Peptides and proteins, Metals, Monomers, lons, 


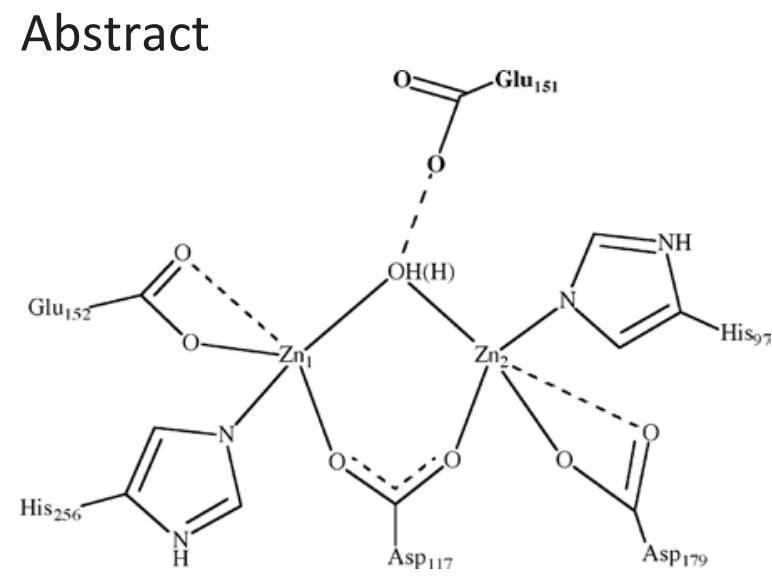

Previous kinetic characterization of the glutamate 151 (E151)-substituted forms of the leucine aminopeptidase from Aeromonas proteolytica (Vibrio proteolyticus; AAP) has provided critical evidence that this residue functions as the general acid/base. The close proximity of similar glutamate residues to the bridging water/hydroxide of the dinuclear active sites of metalloenzymes ( 2.80 and $3.94 \AA$ in carboxypeptidase $\mathrm{G}_{2}$ and 3.30 and $3.63 \AA$ in AAP), suggests it may also be involved in stabilizing the active-site metal ions. Therefore, the structural perturbations of the dinuclear active site of AAP were examined for two E151-substituted forms, namely E151D-AAP and E151A-AAP, by UV-vis and electron paramagnetic resonance (EPR) spectroscopy. UV-vis spectroscopy of Co(II)-substituted E151A-AAP did not reveal any significant changes in the electronic absorption spectra. However UV-vis spectra of mono- and dicobalt(II) E151D-AAP exhibited a lower molecular absorptivity compared to AAP (23 and $43 \mathrm{M}^{-1} \mathrm{~cm}^{-1}$ vs. 56 and $109 \mathrm{M}^{-1} \mathrm{~cm}^{-1}$ for E151D-AAP and AAP, respectively) suggesting both Co(II) ions reside in distorted octahedral coordination geometry in E151D-AAP. EPR spectra of [Co_(E151DAAP)], [ZnCo(E151D-AAP)], and [(CoCo(E151D-AAP)] were identical, with $g_{\perp}=2.35, g_{\|}=2.19$, and $E / D=0.19$, similar to [CoCo(AAP)]. On the other hand, the EPR spectrum of [Co_(E151A-AAP)] was best simulated assuming the presence of two species with (i) $g_{x, y}=2.509, g_{z}=2.19, E / D=0.19, A=0.0069 \mathrm{~cm}^{-1}$ and (ii) $g_{x, y}=2.565, g_{z}=$ 2.19, $E / D=0.20, A=0.0082 \mathrm{~cm}^{-1}$ indicative of a five- or six-coordinate species. Isothermal titration calorimetry experiments revealed a large decrease in $\mathrm{Zn}(\mathrm{II})$ affinities, with $K_{\mathrm{d}}$ values elevated by factors of $\sim 850$ and $\sim 24000$ for the first metal binding events of E151D- and E151A-AAP, respectively. The combination of these data indicates that E151 serves to stabilize the dinuclear active site of AAP.

Abbreviations: rAAP, recombinant leucine aminopeptidase from Aeromonas proteolytica (Vibrio proteolyticus); BuBA, 1-butaneboronic acid; $\mathrm{CPG}_{2}$, carboxypeptidase $\mathrm{G}_{2}$; GCP II, glutamate carboxypeptidase II; HEPES, 4-(2hydroxyethyl)-1-piperazineethanesulfonic acid; IPTG, isopropyl- $\beta$-D-thiogalactopyranoside; ICP-AES, inductively coupled plasma-atomic emission spectrometry; ITC, Isothermal Titration Calorimetry; L- $p$ NA, I-leucine- $p$ nitroanilide; Tricine, $N$-tris[hydroxymethyl]methylglycine; WT, wild type.

\section{Synopsis}

Combination of the kinetic, ITC, and spectroscopic data presented herein has allowed the structural role of glutamate-151 (E151) to be examined. E151 acts on several levels: (i) stabilizing the active site, (ii) preserving the coordination geometry of the first, "tightly bound" metal ion, (iii) affecting the Lewis acidity of the metal ions through the interaction with the bridging water molecule as well as other metal ligands, (iv) positioning the nucleophile relative to the substrate, and ( $v$ ) acting as a general acid in the proposed mechanism of peptide hydrolysis by assisting in the collapse of the tetrahedral intermediate.

Dinuclear metallohydrolases are a large class of enzymes that are capable of degrading peptide, $\beta$-lactam, and ester bonds, making them important components in cellular protein turnover, antibiotic resistance, and 
homeostasis. $\underline{\underline{1-3}}$ These enzymes have been implicated in angiogenesis, protein degradation and processing, neurological disorders, HIV infection, and resistance of bacteria to certain antibiotics. ${ }^{2-7}$ Of particular interest to our research are co-catalytic metallopeptidases from clans M20 and M28-leucine aminopeptidase from Vibrio proteolyticus (AAP; previously miscast as Aeromonas proteolytica), carboxypeptidase $\mathrm{G}_{2}$ from Pseudomonas sp. Strain RS-16 ( $\left.\mathrm{CPG}_{2}\right), \mathrm{N}$-succinyl-I,I-2,6-diaminopimelate desuccinylase (DapE), $\mathrm{N}$-acetyl ornithine deacetylase (ArgE), and glutamate carboxypeptidase II (GCP II) found in humans. ${ }^{1,8,9} \mathrm{CPG}_{2}$ has been successfully used in antibody directed enzyme-prodrug therapy (ADEPT), as well as in rescue therapy following a large dose of administered methotrexate. $\frac{10,11}{\mathrm{GCP}} \mathrm{II}$, which is localized in the brain, liver, kidney, and prostate, is involved in processing of $\mathrm{N}$-acetyl-aspartyl-glutamate (NAAG), a neurotransmitter, and thus is believed to be involved in neurological disorders. ${ }^{1,7,12}$ DapE and ArgE are present only in bacteria and are involved in lysine (DapE) and arginine (ArgE) biosynthesis, making them promising antibacterial targets. ${ }^{8,9,13-}$ 15 While the role of AAP in nature is unknown, it shares high sequence homology to the C-terminal hemagglutinin/protease from $V$. cholerae, a pathogenic microorganism..$^{16}$

Amino acid sequence alignment of the active site regions of metallopeptidases from clans M20 and M28 show a significant degree of similarity (Table 1). Superposition of the active sites of X-ray crystallographically characterized enzymes (aminopeptidase from S. griceus (SAP), AAP, and $\mathrm{CPG}_{2}$ ) reveals an identical and highly conserved architecture of their active sites. $\frac{17-19}{19}$ The co-catalytic active site of AAP, structurally characterized to $1.2 \AA$ resolution contains a ( $\mu$-aquo)( $\mu$-carboxylato)dizinc(II) core with a terminal carboxylate and histidine residue at each metal ion resulting in symmetric coordination spheres for the two active site $\mathrm{Zn}(\mathrm{II})$ ions. $\frac{17,20}{}$ Both $\mathrm{Zn}$ (II) ions reside in distorted tetrahedral coordination geometries with a Zn-Zn distance of $3.5 \AA$. A glutamate residue, E151, forms a hydrogen bond with the bridging water molecule. Although $\mathrm{Zn}(\mathrm{II})$ is the native active-site metal ion for all of these enzymes, studies on AAP and DapE revealed that these enzymes can be activated by several first row transition metals. ${ }^{21,22}$ Bennett and Holz demonstrated that metal binding to AAP occurs in a sequential fashion, $\underline{23}$ highlighting the potential for the formation of heterodimetallic sites. Heterodimetallic centers provide systems in which the function of each metal binding site can be probed through independent labeling with spectroscopically active and silent metal ions.

Table 1. Comparison of Amino Acids in the Active Sites of Selected Dinuclear Metalloenzymes ${ }^{a}$

\begin{tabular}{|c|c|c|c|c|}
\hline AAP & $\mathrm{CPG}_{2}$ & SAP & GCP II & proposed function \\
\hline H97 & H112 & H85 & H377 & $\mathrm{Zn}^{2+}$ binding \\
\hline D99 & D114 & D87 & D379 & hydrogen bonding \\
\hline D117 & D141 & D97 & D387 & $\mathrm{Zn}^{2+}$ binding \\
\hline E151 & E175 & E131 & E424 & general base $^{b}$ \\
\hline E152 & E175 & E131 & E424 & $\mathrm{Zn}^{2+}$ binding \\
\hline D179 & E200 & D160 & D453 & $\mathrm{Zn}^{2+}$ binding \\
\hline $\mathrm{H} 256$ & $\mathrm{H} 385$ & $\mathrm{H} 247$ & $\mathrm{H} 553$ & $\mathrm{Zn}^{2+}$ binding \\
\hline
\end{tabular}

${ }^{a}$ Speno, et al. Mol. Pharmacol.1999, 55, 179-185. ${ }^{b}$ Proposed role.

In the proposed catalytic mechanism of peptide hydrolysis, an important role has been assigned to an active-site glutamate residue (E151) of AAP. This amino acid was recently shown to function as the active-site general acid/base by deprotonating the bridging water molecule, generating a nucleophilic hydroxide, as well as assisting in the collapse of the tetrahedral intermediate, thus facilitating formation of the product. ${ }^{24}$ This glutamate residue is in close proximity to the bridging water species: its oxygen atoms are positioned 3.30 and $3.63 \AA$ ( $A A P)$ and 2.75 and $3.85 \AA\left(C^{2} G_{2}\right)$ from the bridging water/hydroxide, supporting its proposed involvement in the deprotonation of this group. ${ }^{17}$ Additionally, the oxygen atoms of E151 of AAP are $3.2 \AA$ from one of the oxygen atoms of E152, one of the $Z n_{1}$ ligands, and $3.4 \AA$ from the $N^{\varepsilon}$ nitrogen of His97, one of the $\mathrm{Zn}_{2}$ ligands. Therefore, E151 may be involved in the stabilization of the active site. To understand the structural 
perturbations of the $\mathrm{Zn}(\mathrm{II})$ ions in the active site of AAP upon substitution of E151 with an aspartate or an alanine residue, we have recorded the electronic absorption and EPR spectra of Co(II)-substituted forms of these enzymes. In addition, isothermal titration calorimetry (ITC) was used to determine the metal binding constants in rAAP, as well as the E151D and E151A variants of AAP. Combination of the data presented herein indicates that E151 is crucial for the stability of the active site, most likely through hydrogen-bonding interactions with the residues in the active site of AAP.

\section{Materials and Methods}

\section{Protein Expression and Purification.}

All materials used in this study were of the highest purity available and were purchased from Fisher or SigmaAldrich, unless stated otherwise. The E151D and E151A forms of AAP were prepared and purified as described elsewhere. $\underline{25}$

\section{Enzymatic Assay.}

During and after purification, the E151D and E151A forms of AAP were assayed for catalytic activity with Ileucine- $p$-nitroanilide (L-pNA) as the substrate..$^{26}$ In this assay, the hydrolysis of L-pNA was measured spectrophotometrically by monitoring the formation of $p$-nitroaniline at $405 \mathrm{~nm}\left(\varepsilon=10800 \mathrm{M}^{-1} \mathrm{~cm}^{-1}\right)$ in a cell with a 1-cm light path. All assays were performed on a Shimadzu UV-3101PC spectrophotometer equipped with a constant-temperature cell holder and an Isotemp 2013D water bath (Fisher Scientific, Pittsburgh, PA). Enzyme concentrations were determined from the absorbance at $280 \mathrm{~nm}$ with the value $\varepsilon_{280}=43950 \mathrm{M}^{-1} \mathrm{~cm}^{-1}$. $\underline{27}$ All assays were performed at $25 \pm 0.1{ }^{\circ} \mathrm{C}$ unless stated otherwise. All experiments were carried out in $10 \mathrm{mM}$ Tricine buffer $\mathrm{pH} 8.0$ with $0.1 \mathrm{mM} \mathrm{ZnSO}_{4}$, unless stated otherwise.

\section{Apo-Enzyme Preparation.}

Purified and concentrated E151A-AAP or E151D-AAP $(10-20 \mathrm{mg} / \mathrm{mL})$ was incubated with $10-15 \mathrm{mM}$ disodium EDTA at $4{ }^{\circ} \mathrm{C}$ until no activity was observed (usually 1-3 days). To remove EDTA, the protein was dialyzed extensively against 100 times the volume of chelexed 50 mM HEPES buffer pH 7.5 (Chelex 100, BioRad). The activity of the dialyzed apo-E151D-AAP was less than 1\% of the activity of the enzyme reconstituted with 2 equiv of Zn(II); metal content in the E151A form of AAP was determined by ICP-AES analysis (USU Agriculture Department). All plastic-ware used for dialysis and the dialysis tubing were presoaked in a disodiumEDTA/bicarbonate solution to remove all traces of metals and then extensively washed with Nanopure water (NANOpure Ultrapure Water System, Barnstead/Thermolyne, IA) and chelexed HEPES buffer.
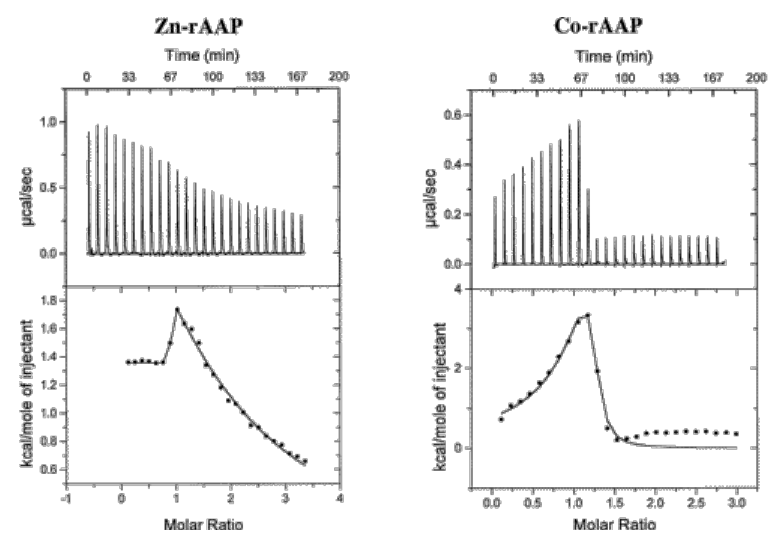

Figure 1 Isothermal titration data for the titration of apo-rAAP with (left) Zn(II) and (right) Co(II) (50 mM HEPES buffer $\mathrm{pH} 7.5$ at $\left.25^{\circ} \mathrm{C}\right)$. 


\section{Isothermal Titration Calorimetry.}

ITC measurements were carried out on a MicroCal OMEGA ultrasensitive titration calorimeter at $25 \pm 0.2{ }^{\circ} \mathrm{C}$. Association constants $\left(K_{\mathrm{a}}\right)$ were obtained by fitting these data, after subtraction of the background heat of dilution, via an interactive process using the Origin software package. This software package uses a nonlinear least-squares algorithm, which allows the concentrations of the titrant and the sample to be fit to the heat-flowper-injection to an equilibrium binding equation for two noninteracting sites. The $K_{\mathrm{a}}$ value, enzyme-metal stoichiometry $(n)$, and the change in enthalpy $\left(\Delta H^{\circ}\right)$ were allowed to vary during the fitting process. The divalent metal ion titrants and apo-enzyme solutions were prepared in chelexed HEPES buffer at pH 7.5. Stock buffer solutions were thoroughly degassed before each titration. The enzyme solution (60-90 $\mu \mathrm{M})$ was placed in the calorimeter cell and stirred at $200 \mathrm{rpm}$ to ensure rapid mixing. Typically, 4-6 $\mu \mathrm{L}$ of titrant was delivered over 7.6 $\mathrm{s}$ with a 6 min interval between injections to allow for complete equilibration. Each titration was continued until 4.5-6 equiv of $M(I I)$ had been added to ensure that no additional complexes were formed in excess titrant. A background titration, consisting of the identical titrant solution but only the buffer solution in the sample cell, was subtracted from each experimental titration to account for heat of dilution. These data were analyzed with a two- or three-site binding model by the Windows-based Origin software package supplied by MicroCal. The heat of reaction, measured during the experiment, was converted into association constants $\left(K_{\mathrm{a}}\right)$ using the Gibbs free energy relationship:

$$
\Delta G^{\circ}=-R T \ln \left(K_{\mathrm{a}}\right)=\Delta H^{\circ}-T \Delta S^{\circ}
$$

where $R=1.9872 \mathrm{cal} \mathrm{mol}^{-1} \mathrm{~K}^{-1}$. The relationship between $K_{\mathrm{a}}$ and $K_{\mathrm{d}}$ is defined as

$$
K_{\mathrm{d}}=1 / K_{\mathrm{a}}
$$

(2)

Individual rAAP and altered rAAP enzyme solutions were prepared by diluting stock enzyme solutions with 50 $\mathrm{mM}$ chelexed HEPES buffer ( $\mathrm{pH}$ 7.5).

\section{Spectroscopic Measurements.}

Electronic absorption spectra were recorded on a Shimadzu UV-3101PC spectrophotometer. All solutions used for the experiment were degassed prior to use. The apo-protein (typically 0.3-1.2 mM) was incubated with Co(II) $\left(\mathrm{CoCl}_{2}: \geq 99.999 \%\right.$ Acros Organics, Geel, Belgium) for $\sim 10 \mathrm{~min}$ at $25^{\circ} \mathrm{C}$ before a spectrum was recorded. The apo-enzyme absorbance was subtracted from the spectra obtained with Co(II) using IgorPro (Wavemetrix, Inc., Lake Oswego, OR). EPR spectra were recorded using a Bruker ESP-300E spectrometer with an ER 4116 DM $\mathrm{TE}_{102} / \mathrm{TE}_{012}$ dual-mode $\mathrm{X}$-band cavity and an Oxford Instruments ESR-900 helium flow cryostat. All spectra were recorded at a modulation frequency of $100 \mathrm{kHz}$ and a modulation amplitude of $12.6 \mathrm{G}$ (1.26 mT). Protein concentrations used for EPR experiments were approximately $1 \mathrm{mM}$. Exact microwave frequencies and temperatures for individual spectra are provided in the figure legends. Computer simulations of EPR spectra were carried out using Xsophe v.1.1.2 (Bruker Biospin GmbH, Rheinstetten, Germany). .2 Parameters were fit to the spin Hamiltonian:

$$
H=\beta \mathrm{gHS}+\mathrm{SDS}+\mathrm{SAI}
$$

Under this formalism, $D>0$ corresponds to an $M_{\mathrm{s}}=| \pm 1 / 2\rangle$ ground state and $D<0$ corresponds to an $M_{\mathrm{s}}=$ $| \pm 3 / 2\rangle$ ground state. 


\section{Results}

Enzymatic Activity of E151D- and E151A-AAP.

The observed $k_{\text {cat }}$ value for E151D-AAP is $2.24 \mathrm{~min}^{-1}$, which is 1900 times slower than that of rAAP (10 mM Tricine buffer, $\mathrm{pH}$ 8.0, $0.2 \mathrm{M} \mathrm{KCl}, 0.1 \mathrm{mM} \mathrm{ZnSO}_{4}$ ); however, E151A-AAP is completely inactive. ${ }^{24,25}$ Interestingly, the observed $K_{m}$ value for E151D-AAP is identical, within error, to WT AAP.

\section{Metal Binding Properties of rAAP, E151D-, and E151A-AAP.}

The best fits obtained for rAAP upon the addition of either $\mathrm{Zn}$ (II) or Co(II) provided $n$ values of 2 for two noninteracting sites (Figure 1; Table 2). The first binding site exhibited a $K_{\mathrm{d}}$ value of $0.003 \mu \mathrm{M}$ for $\mathrm{Zn}(\mathrm{II})$ and 0.09 $\mu \mathrm{M}$ for $\mathrm{Co}(\mathrm{II})$ binding. These data are in good agreement with the $K_{\mathrm{d}}$ value determined for the binding of a single $\mathrm{Zn}(\mathrm{II})$ ion by Baker and Prescott using equilibration dialysis $(0.00015 \mu \mathrm{M}) . \underline{29}$ The observed $K_{\mathrm{d}}$ values for $\mathrm{Zn}(\mathrm{II})$ and $\mathrm{Co}$ (II) binding to the second metal binding site for rAAP are $0.25 \mathrm{mM}$ and $0.36 \mu \mathrm{M}$, respectively. The energy change observed for both binding sites indicates an endothermic-type reaction providing a more positive $\Delta H$ value for the second metal binding event; however, it is evident that the metal-ion binding process is entropy-driven (Table 2). For E151D-AAP, Zn(II) and Co(II) binding provided one tight metal binding site with $K_{\mathrm{d}}$ values of 2.7 and $14 \mu \mathrm{M}$, respectively, and one loose metal binding site which exhibited $K_{\mathrm{d}}$ values of 5.9 and $2.5 \mathrm{mM}$ for $\mathrm{Zn}(\mathrm{II})$ and $\mathrm{Co}$ (II) binding, respectively. The first and second $\mathrm{Zn}$ (II) and Co(II) binding events were endothermic (Table 2). For E151A-AAP, the best fit revealed two $\mathrm{Zn}(\mathrm{II})$ binding sites that exhibited $K_{\mathrm{d}}$ values of 75 and $429 \mu \mathrm{M}$ for the first and second binding events, respectively. Similar to WT rAAP, the observed energy change for both the first and second $\mathrm{Zn}$ (II) ion binding events is endothermic (Table 2). An interesting pattern can be seen-binding of the first metal ion exhibits more negative Gibbs free energy, as compared to the second binding event, while binding of the second metal ion is largely entropy driven.

Table 2. Metal Binding Constants and Thermodynamic Parameters for Co(II) and Zn(II) Binding to Apo E151D, E151A, and Recombinant AAP

\begin{tabular}{|l|l|l|l|l|l|}
\hline & $n^{a}$ & $K_{1}, K_{2}\left(\mathrm{M}^{-1}\right)$ & $\Delta H_{1}, \Delta H_{2}\left(\mathrm{kcal} \mathrm{mol}^{-1}\right)$ & $T \Delta S_{1}, T \Delta S_{2}\left(\mathrm{kcal} \mathrm{mol}^{-1}\right)$ & $\Delta G_{1}, \Delta G_{2}\left(\mathrm{kcal} \mathrm{mol}^{-1}\right)$ \\
\hline$[$ CoCo(E151D) $]$ & 0.89 & $7.11 \times 10^{4}$ & 1.25 & 7.88 & -6.63 \\
\hline & 1.28 & $3.99 \times 10^{2}$ & 7.27 & 10.82 & -3.55 \\
\hline$[$ ZnZn(E151D)] & 1.02 & $3.76 \times 10^{5}$ & 3.82 & 11.44 & -7.62 \\
\hline & 1.05 & $1.10 \times 10^{2}$ & 1.25 & 4.03 & -3.05 \\
\hline$[$ ZnZn(E151A)] & 1.30 & $1.34 \times 10^{2}$ & 1.89 & 7.52 & -5.63 \\
\hline & 1.12 & $2.33 \times 10^{4}$ & 20.7 & 25.3 & -4.59 \\
\hline$[$ CoCo(rAAP)] & 0.97 & $1.06 \times 10^{7}$ & 0.21 & 9.71 & -9.50 \\
\hline & 0.90 & $2.77 \times 10^{6}$ & 10.03 & 18.45 & -8.42 \\
\hline [ZnZn(rAAP)] & 1.21 & $3.19 \times 10^{8}$ & 1.36 & 12.95 & -11.59 \\
\hline & 1.05 & $3.93 \times 10^{3}$ & 5.23 & 10.14 & -4.91 \\
\hline
\end{tabular}

${ }^{a} n$, enzyme-metal stoichiometry; $K_{i}$, dissociation constant.

Electronic Absorption Spectra of rAAP, E151D-, and E151A-AAP.

Electronic absorption spectra of the mono- and dicobalt(II) forms of rAAP, E151D-AAP, and E151A-AAP were recorded in $50 \mathrm{mM}$ chelexed HEPES buffer, $\mathrm{pH}$ 7.5, and the component due to apo-AAP was subtracted (Table 3; Figure 3). Similar to WT AAP, the addition of one Co(II) ion to rAAP provides a visible absorption spectrum with a band at $525 \mathrm{~nm}\left(\varepsilon_{525} \approx 56 \mathrm{M}^{-1} \mathrm{~cm}^{-1}\right)$. The addition of a second equivalent of Co(II) increases the absorption intensity at $525 \mathrm{~nm}$ to $\sim 109 \mathrm{M}^{-1} \mathrm{~cm}^{-1}$. The addition of more than 2 equiv of Co(II) does not significantly alter the intensity or position of the observed absorption band. A portion of the added absorptivity $\left(\Delta \varepsilon_{525}\right.$ of $\left.53 \mathrm{M}^{-1} \mathrm{~cm}^{-1}\right)$ appears to be due to a broad underlying protein absorption band that is not due to Co(II) absorption $\left(\varepsilon_{425}=15\right.$ $\left.\mathrm{M}^{-1} \mathrm{~cm}^{-1}\right)$. Therefore, the observed increase in absorption at $525 \mathrm{~nm}$ due to the second Co(II) ion is $\sim 38 \mathrm{M}^{-1} \mathrm{~cm}^{-1}$. 
The molar absorptivities and absorption maxima are consistent with the first $\mathrm{Co}$ (II) ion residing in a distorted five-coordinate environment, while the second $\mathrm{Co}$ (II) ion resides in either a distorted five-coordinate or a very distorted octahedral environment. These spectra are similar to those recorded by Prescott and co-workers. $\stackrel{30}{*}$ For Co(II)-loaded E151D-AAP, the visible absorption spectrum revealed a band at $521 \mathrm{~nm}$ with an $\varepsilon$ value of $23 \mathrm{M}^{-}$ ${ }^{1} \mathrm{~cm}^{-1}$ for [Co_(E151D-AAP)]. Upon the addition of a second equivalent of $\mathrm{Co}(\mathrm{II})$, the $\lambda_{\max }$ did not shift but the molar absorptivity increased to $43 \mathrm{M}^{-1} \mathrm{~cm}^{-1}$. On the other hand, the absorption maximum observed for [Co_(E151A-AAP)] is $523 \mathrm{~nm}$ with a molar absorptivity of $48 \mathrm{M}^{-1} \mathrm{~cm}^{-1}$ and a shoulder at $570 \mathrm{~nm}$. The addition of a second equivalent of $\mathrm{Co}(\mathrm{II})$ increased the molar absorptivity to $79 \mathrm{M}^{-1} \mathrm{~cm}^{-1}$.
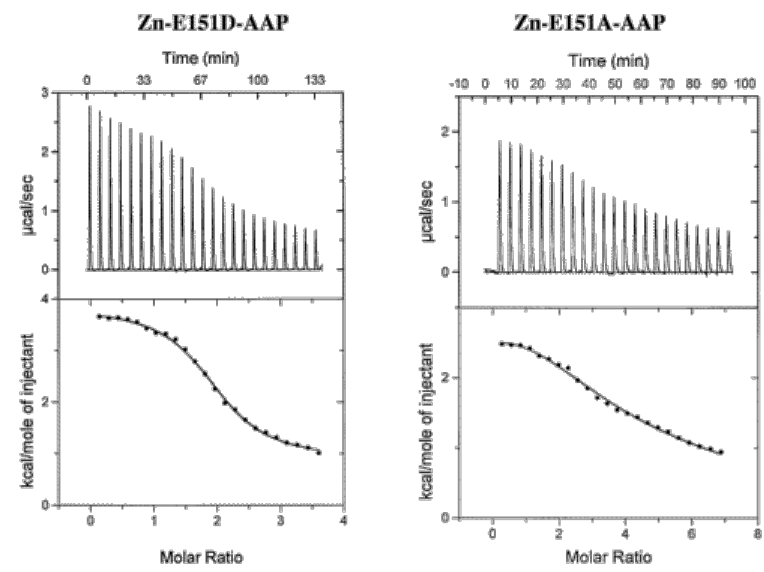

Figure 2 Isothermal titration data for the titration of (A) apo-E151D-AAP and (B) apo-E151A-AAP with Zn(II) (50 mM HEPES buffer $\mathrm{pH} 7.5$ at $25^{\circ} \mathrm{C}$ ).

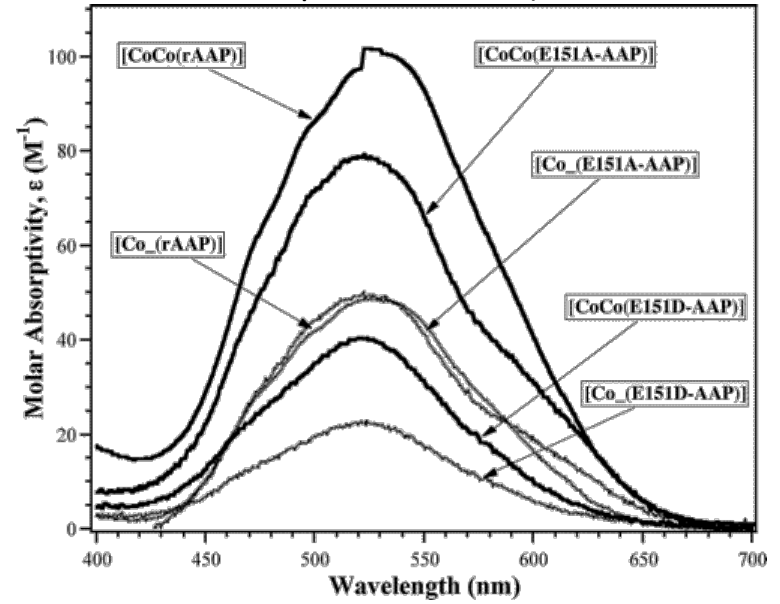

Figure 3 UV-vis spectra of rAAP, E151D-AAP, and E151A-AAP with Co(II) in 50 mM HEPES, pH 7.50.

Table 3. Comparison of Spectral Properties of rAAP and E151D, E151A AAP ${ }^{a}$

\begin{tabular}{|l|l|l|l|}
\hline & rAAP & E151D & E151A \\
\hline maximum absorbance $(\mathrm{nm})$ & 525 & 521 & 523 \\
\hline molar absorptivity with 1 equiv of $\mathrm{Co}(\mathrm{II})\left(\mathrm{M}^{-1} \mathrm{~cm}^{-1}\right)$ & 56 & 23 & 48 \\
\hline molar absorptivity with 2 equiv of $\mathrm{Co}(\mathrm{II})\left(\mathrm{M}^{-1} \mathrm{~cm}^{-1}\right)$ & 109 & 43 & 79 \\
\hline
\end{tabular}

${ }^{a}$ Metal titration experiments were carried out in chelexed $50 \mathrm{mM} \mathrm{HEPES}$, pH 7.5 with $\mathrm{CoCl}_{2}$ (99.999\% Acros Organics, Geel, Belgium). Protein concentration ranged from 0.6 to $1.2 \mathrm{mM}$

EPR Characterization of rAAP, E151D- and E151A-AAP. EPR spectra of [CoZn(E151D-AAP)], [ZnCo(E151D-AAP)], and [CoCo(E151D-AAP)] recorded at $10 \mathrm{~K}$ are indistinguishable (Figure 4). rAAP spectra are identical to those of WT AAP. ${ }^{23,31}$ Each of these spectra could be 
simulated with $g_{\perp}($ real $)=2.35$ and $g_{\|}($real $) \approx 2.38$ and $E / D=0.1$ with $D \gg g \beta H$ (Figure 4). On the other hand, EPR spectra of [Co_(E151A-AAP)] revealed the presence of resolved ${ }^{59} \mathrm{Co}$ hyperfine lines, as is the case with [Co_(WTAAP)], suggesting the presence of an additional rhombic species with $g_{\perp}($ real $) \approx 2.5, E / D \approx 0.2$ and $A\left({ }^{59} \mathrm{Co}\right) \approx 0.0075 \mathrm{~cm}^{-1}$ (Figure 5). These data were best simulated with models including two distinct species of equal intensities, with (i) $g_{x, y}=2.509, g_{z}=2.19, E / D=0.19, A=0.0069 \mathrm{~cm}^{-1}$; (ii) $g_{x, y}=2.565, g_{z}=2.19, E / D=$ $0.20, A=0.0082 \mathrm{~cm}^{-1}$. The quality of the simulation can be judged by the reproduction of the hyperfine pattern in the high-resolution EPR spectrum (Figure 5). For [CoCo(E151A-AAP)], a broad rhombic signal is observed similar to [CoCo(WTAAP)] and was simulated with $g_{x, y}=2.29, g_{z} \approx 2.55 ; E / D=0.08$ (Figure 6).

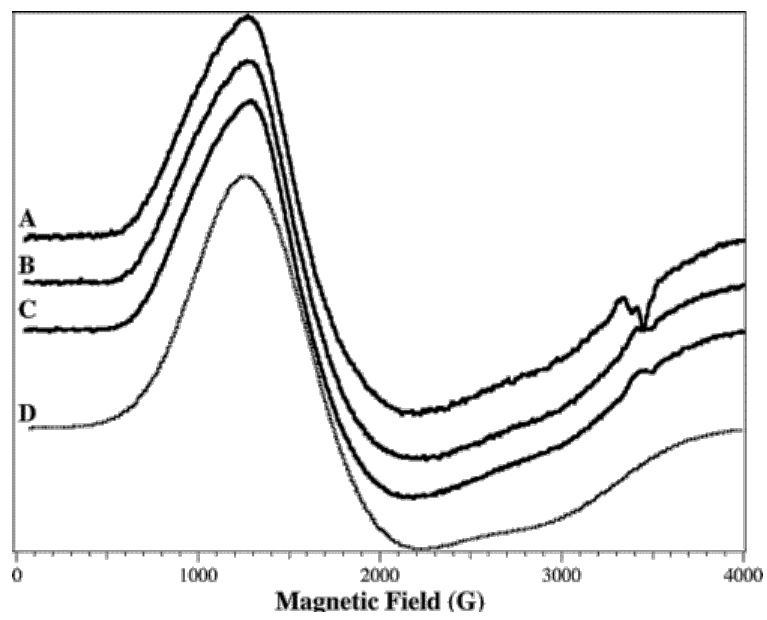

Figure 4 EPR spectra of metal-reconstituted E151D-AAP, pH 7.50. All spectra were recorded at $10 \mathrm{~K}, 0.2 \mathrm{~mW}$ microwave power, $12.6 \mathrm{G}$ field modulation amplitude, $100 \mathrm{kHz}$ modulation frequency. (A) EPR spectrum of [CoZn(E151D-AAP)]; (B) EPR spectrum of [ZnCo(E151D-AAP)]; (C) EPR spectrum of [CoCo(E151D-AAP)]; (D) simulation of the spectra with $g_{x, y}=2.35$ and $g_{z}=2.38, E / D=0.1$.

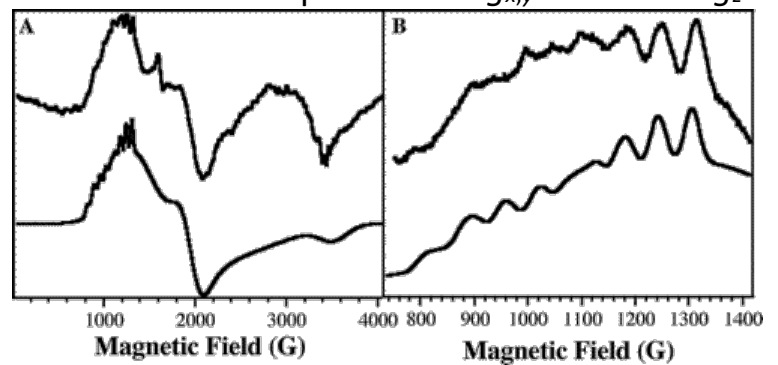

Figure 5 (A) Top: EPR spectrum of [Co_(E151A-AAP)] in HEPES buffer, pH 7.50 recorded at $10 \mathrm{~K}, 0.2 \mathrm{~mW}$ microwave power, $12.6 \mathrm{G}$ field modulation amplitude, $100 \mathrm{kHz}$ modulation frequency. Bottom: simulation of the EPR spectrum of [Co_(E151A-AAP)] with three species: (1) $g_{x, y}=2.509, g_{z} \approx 2.19, E / D=0.19, A=0.0069 \mathrm{~cm}^{-1}$; (2) $g_{x, y}=2.565, g_{z} \approx 2.19, E / D=0.20, A=0.0082 \mathrm{~cm}^{-1}$; (3) $g_{x, y}=2.29, g_{z} \approx 2.55, E / D=0.08$. (B) Low-field region of the spectrum recorded at higher resolution and a correspondingly expanded view of the simulation. 


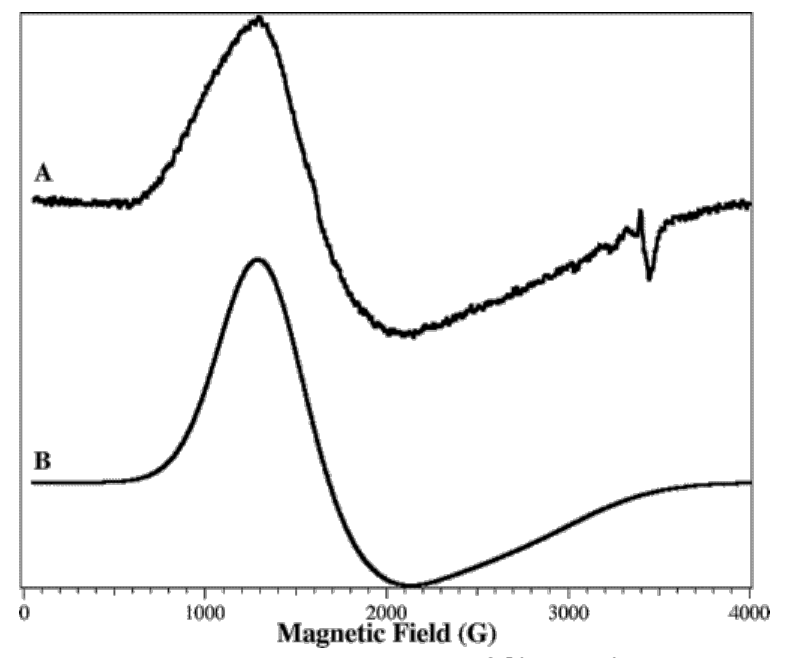

Figure 6 Top: EPR spectrum of [(CoCo(E151A-AAP)] in HEPES buffer, pH 7.50 recorded at $10 \mathrm{~K}, 0.2 \mathrm{~mW}$ microwave power, $12.6 \mathrm{G}$ field modulation amplitude, $100 \mathrm{kHz}$ modulation frequency. Bottom: simulation of the EPR spectrum of [CoCo(E151A-AAP)] with $g_{x, y}=2.29, g_{z} \approx 2.55, E / D=0.08$.

\section{Discussion}

In recent years, a significant amount of attention has been directed toward understanding the catalytic mechanism of dinuclear metallohydrolases because of their involvement in numerous biological processes. Although most healthy organisms maintain homeostasis, in an abnormal state, such as cancer, the tight control of many processes does not occur. Therefore, understanding the mechanism by which peptides are hydrolyzed may ultimately lead to the discovery of drugs that help combat health conditions such as neurological disorders, cancer, and diseases caused by antibiotic-resistant bacteria. One of the enzymes in this group that has been extensively characterized by kinetic, spectroscopic, and X-ray crystallographic studies is the amino peptidase from $A$. proteolytica ( $V$. proteolyticus; AAP). One active-site residue that is of particular interest is glutamate-151 (E151) since it has been shown to function as the active-site general acid/base. ${ }^{24}$ The proximity of the bridging water molecule and metal ion ligands-H97 and E152 suggests that E151 may also stabilize the dinuclear active site and play a role in tuning the Lewis acidity of the active site $\mathrm{Zn}(\mathrm{II})$ ions. Therefore, we have used a combination of kinetic, thermodynamic, and spectroscopic data to evaluate the structural role of E151.

On the basis of kinetic data with Zn(II)-loaded enzymes, substitution of E151 with an aspartate results in a 2000fold decrease in $k_{\text {cat, }}$ whereas substitution of E151 with an alanine results in an inactive enzyme. ${ }^{24}$ Although not a ligand to the metal ions in the dinuclear Zn(II) active site, metal binding studies indicate that substituting E151 markedly affects the metal-binding properties. ITC data indicate that, when E151 is substituted with aspartate, $\mathrm{Zn}$ (II) binds $\sim 850$ times more weakly compared to rAAP. Similarly, substitution of E151 with an alanine residue, which cannot form hydrogen bonds within the active site, weakens the binding of the first $\mathrm{Zn}$ (II) ion by a staggering 24000 times. The largest change in Gibbs free energy can be observed in the first Zn(II) binding event, with rAAP being the most- and E151A-AAP the least-exoenergetic process. These data correlate with the activity measurements with rAAP being the most- and E151A-AAP the least-active and strongly suggest that the first metal binding site accommodates the catalytically relevant metal ion. This seemingly unexpected correlation, as E151 is not a direct ligand to the metal ions, underscores the importance of second-shell interactions in the active site of metalloenzymes. Mutation of the residue in position 151 does not affect the binding of the second $\mathrm{Zn}(\mathrm{II})$, and overall free energy is similar for rAAP, E151A-, and E151D-AAP. Substitution of residue 151 has similar effects on $\mathrm{Co}$ (II) binding, weakening the interaction of metal ion with the active site of the enzyme. In contrast to $\mathrm{Zn}$ (II) binding to rAAP, the two Co(II) bind to the enzyme with similar affinities. However binding of Co(II) to E151D-AAP is only 150 times weaker for the first metal binding site but $~ 7000$ 
times weaker for the second equivalent of Co(II) compared to rAAP. Clearly, E151 is an important regulator of the electron density around the active site metal ions.

Even though the metal $K_{\mathrm{d}}$ values are markedly affected by the elimination of E151, no major geometrical changes are observed on the basis of electronic absorption spectra of Co(II)-substituted AAP enzymes; however, the observed molar absorptivities for [Co_(E151D-AAP)] and [CoCo(E151D-AAP)] are approximately half those observed for rAAP. Electronic absorption spectra of [Co_(E151A-AAP)] and [CoCo(E151A-AAP)] are similar to those of rAAP, but the molar absorptivities are higher than those observed for Co(II)-loaded E151D-AAP. The presence of a shoulder with $\lambda_{\max }$ at $570 \mathrm{~nm}$ suggests an additional electronic transition, probably due to distortion about the Co(II) ions. Consistent with electronic absorption spectra, EPR data obtained on [CoCo(E151A-AAP)] suggest a rigid, pentacoordinate environment for the first metal ion. Further coordination environment changes in the active site of E151D-AAP were obtained by recording the EPR spectrum of [Co_(E151D-AAP)], which is very similar to that of $[\mathrm{CoCo}(\mathrm{AAP})]\left(g_{\perp}(\right.$ real $)=g_{\|}($real $) \approx 2.29$ and $\left.E / D=0.08\right)$, but differs significantly from those of [Co_(AAP)], [CoZn(AAP)], and [ZnCo(AAP)] in that there was no rhombic component that exhibits resolved hyperfine coupling. ${ }^{23}$ For [Co_(E151D-AAP)], the intensity of the electronic transition observed at $521 \mathrm{~nm}\left(23 \mathrm{M}^{-1} \mathrm{~cm}^{-1}\right)$ and a featureless EPR signal, notably lacking the rhombic signal seen in the spectrum of a [Co_(AAP)], indicate clear differences between E151D-AAP and wild-type or rAAP.

There are three possible explanations for the unusual spectroscopic behavior of E151D-AAP. First, it is possible that the $\mathrm{Co}(\mathrm{II})$ ions bind cooperatively. In this case, samples of [Co_(E151D-AAP)] would really contain 50\% [CoCo(E151D-AAP)] and 50\% apo-E151D-AAP while samples of [CoZn(E151D-AAP)] and [ZnCo(E151D-AAP)] would really contain 50\% [CoCo(E151D-AAP)] and [ZnZn(E151D-AAP)]. This scenario would explain the EPR data adequately but not the electronic absorption data. A second explanation would consist of hexacoordinate binding site for the first $\mathrm{Co}$ (II) ion in E151D-AAP rather than pentacoordinate. This would explain the electronic absorption data and be consistent with the EPR of [Co_(E151D-AAP)] and [CoZn(E151D-AAP)]. However, the EPR signal from [ZnCo(E151D-AAP)] would be expected to resemble that of the corresponding wild-type species; it clearly does not. The third scenario would explain all the EPR data and the optical data but invokes a combination of the first two explanations. If the "first" site is actually hexacoordinate (for Co(II)) in E151D-AAP and $\mathrm{Co}$ (II) binds to this site cooperatively, then the EPR and optical data can be explained on the basis that a doubly hexacoordinate [CoCo(E151D-AAP)] species, which is the only species observed in the EPR and optical spectroscopic measurements. The most likely sixth ligand for $\mathrm{Co}_{1}$ would be a water molecule that is hydrogenbonded to D151. The presence of two slightly different species in the spectrum of [Co_(E151A-AAP)] has also been observed in wild-type AAP under the conditions used and one of the species likely represents only a small perturbation of the other by an $\mathrm{OH}^{-} / \mathrm{H}_{2} \mathrm{O}$ equilibrium. ${ }^{23,31}$

In conclusion, the combination of kinetic, ITC, and spectroscopic data has allowed the structural role of E151 to be examined. E151 acts on several levels: (i) stabilizing the active site, (ii) preserving the coordination geometry of the first, "tightly bound" metal ion, (iii) affecting the Lewis acidity of the metal ions through the interaction with the bridging water molecule, as well as other metal ligands, (iv) positioning the nucleophile relative to the substrate, and ( $v$ ) acting as a general acid in the proposed mechanism of peptide hydrolysis by assisting in the collapse of the tetrahedral intermediate. ${ }^{24}$ The combination of data presented herein with previously reported kinetic data ${ }^{24}$ highlights the complexity of first and second sphere interactions that occur in the active sites of metalloenzymes. These data also provide additional insight into our understanding of the role active site residues (both metal ligands and nonligands) play in the hydrolysis of peptides by metalloenzymes that contain dinuclear active sites. 


\section{Acknowledgment}

This work was supported by the National Science Foundation (CHE-0240810, R.C.H.) and the National Institutes of Health (AI-056231, B.B.). The Bruker ESP-300E EPR spectrometer was purchased with funds provided by the National Science Foundation (BIR-9413530), and XSophe was purchased with funds from the National Institutes of Health (NIH RR01008, B.B.).

\section{References}

1 Barrett, A. J.; Rawlings, N. D.; Woessner, J. F.; Eds. Handbook of proteolytic enzymes; Academic Press: London, 1998.

2 Taylor, A. FASEB J.1993, 7, 290-298.

3 Taylor, A. TIBS1993, 18, 167-172.

4 Pulido-Cejudo, G.; Conway, B.; Proulx, P.; Brown, R.; Izaguirre, C. A. Antivir. Res.1997, 36, 167-177.

5 Crowder, M. W.; Wang, Z.; Franklin, S. L.; Zovinka, E. P.; Benkovic, S. J. Biochemistry1996, 35, 12126-12132.

6 Fabiane, S. M.; Sohi, M. K.; Wan, T.; Payne, D. J.; Bateson, J. H.; Mitchell, T.; Sutton, B. J. Biochemistry1998, 37, 12404-12411.

7 Slusher, B. S.; Vornov, J. J.; Thomas, A. G.; Hurn, P. D.; Harukuni, I.; Bhardvaj, A.; Traystman, R. J.; Robinson, M. B.; Britton, P.; Lu, X. C.; Tortella, F. C.; Wozniak, K. M.; Yudkoff, M.; Potter, B. M.; Jackson, P. F. Nat. Med.1999, 5, 1396-1402.

8 Born, T. L.; Zheng, R.; Blanchard, J. S. Biochemistry1998, 37, 10478-10487.

9 Javid-Majd, F.; Blanchard, J. S. Biochemistry2000, 39, 1285-1293.

10 Martin, J.; S. M., S.; G. K., P.; R. H., B.; M., N.; S. K., S.; C. J., S. Cancer Chemother. Pharmacol.1997, 40, 189-201.

11 Francis, R. J.; S. S. K.; Springer, C.; Green, A. J.; Hope-Stone, L. D.; Sena, L.; Martin, J.; Adamson, K. L.; Robbins, A.; Gumbrell, L.; O'Malley, D.; Tsiompanou, E.; Shahbakhti, H.; Webley, S.; Hochhauser, D.; Hilson, A. J.; Blakey, D.; Begent, R. H. Br. J. Cancer2002, 87, 600-607.

12 Tiffany, C. W.; Lapidus, R. G.; Merion, A.; Calvin, D. C.; Slusher, B. S. Prostate1999, 39, 28-35.

13 Scapin, G.; Blanchard, J. S. Adv. Enzymol.1998, 72, 279-325.

14 Ledwidge, R.; Blanchard, J. S. Biochemistry1999, 38, 3019-3024.

15 Born, T. L.; Blanchard, J. S. Cur. Opin. Chem. Biol.1999, 3, 607-613.

16 Naka, A.; Yamamoto, K.; Miwatani, T.; Honda, T. FEMS Microbiol. Lett.1992, 77, 197-200.

17 Chevrier, B.; Schalk, C.; D'Orchymont, H.; Rondeau, J.-M.; Moras, D.; Tarnus, C. Structure1994, 2, 283-291.

18 Rowsell, S.; Pauptit, R. A.; Tucker, A. D.; Melton, R. G.; Blow, D. M.; Brick, P. Structure1997, 5, 337-347.

19 Greenblatt, H. M.; Almog, O.; Maras, B.; Spungin-Bialik, A.; Barra, D.; Blumberg, S.; Shoham, G. J. Mol. Biol.1997, 265, 620-636.

20 Desmarais, W.; Bienvenue, L. D.; Bzymek, K.; Holz, R. C.; Petsko, A. G.; Ringe, D. Structure2002, 1063-1072.

21 Bienvenue, D. L.; Gilner, D. M.; Davis, R. S.; Bennett, B.; Holz, R. C. Biochemistry2003, 42, 10756-10763.

22 Bayliss, M. E.; Prescott, J. M. Biochemistry1986, 25, 8113-8117.

23 Bennett, B.; Holz, R. C. J. Am. Chem. Soc.1997, 119, 1923-1933.

24 Bzymek, K. P.; Holz, R. C. J. Biol. Chem.2004, 279, 31018-31025.

25 Bzymek, K. P.; D'souza, V. M.; Chen, G.; Campbell, H.; Mitchell, A.; Holz, R. C. Protein Express. Purif.2004, 37/2, 294-305.

26 Prescott, J. M.; Wilkes, S. H. Methods Enzymol.1976, 45, 530-543.

27 Prescott, J. M.; Wilkes, S. H.; Wagner, F. W.; Wilson, K. J. J. Biol. Chem.1971, 246, 1756-1764.

28 Griffin, M.; Muys, A.; Noble, C.; Wang, D.; Eldershaw, C.; Gates, K. E.; Burrage, K.; Hanson, G. R. Mol. Phys. Rep.1999, 26, 60-64.

29 Baker, J. O.; Prescott, J. M. Biochem. Biophys. Res. Commun.1985, 130, 1154-1160.

30 Prescott, J. M.; Wagner, F. W.; Holmquist, B.; Vallee, B. L. Biochemistry1985, 24, 5350-5356.

31 Bennett, B.; Holz, R. C. Biochemistry1997, 36, 9837-9846. 